\title{
Video documental en antropología
}

\author{
Victoria Novelo O.
}

\section{ALGUNAS REFERENCIAS COMO INTRODUCCIÓN NECESARIA}

$\mathrm{S}$
OY DEFINITIVAMENTE una fanática del cine y además, estoy convencida de sus inmensas bondades, posibilidades y potencialidades como apoyo didáctico, fuente de información, divulgador de conocimientos y propuesta estética, además de su capacidad de divertir, emocionar y provocar la reflexión. El cine, precisamente por sus propiedades envolventes y su capacidad de sintetizar las artes conocidas que apelan a todos los sentidos, me ha interesado como herramienta de trabajo en el ejercicio de mi profesión como antropóloga social. Desde ese punto de vista es que me interesa la discusión de los alcances y limitaciones que tiene el medio cinematográfico en la producción de conocimiento, $\mathrm{CO}$ mo divulgador y también como deformador (o hasta "traidor") del discurso de la investigación antropológica tradicional cuando se la "traduce" al lenguaje cinematográfico. Quiero aclarar que cuando hablo de cine me refiero al lenguaje filmico en general, es decir, un modo de registro gráfico que capta el movimiento, además de la luz y el sonido con lo cual supera, a mi modo de ver, a otros medios de documentación y donde queda incluido, desde su invención, el video, formato que aunque

victoria novelo o.: CIESAS / Universidad de Colima.

Desacatos, núm. 8, invierno 2001, pp. 48-60. tiene sus peculiaridades, es una manera más sencilla y barata de filmar que el cine común profesional.

En 1999, coherente con mi antigua inquietud por difundir en lenguajes más accesibles al público los conocimientos que mis investigaciones antropológicas van produciendo, propuse en el CIESAS el proyecto "Antropo-visiones", un proyecto cuyo objetivo es constituir una serie para televisión con programas en video a partir de los resultados del trabajo de investigación que se hace en el CIESAS. El proyecto, que ya va en su cuarto programa (y tiene dos más en posproducción), se dirige a un público amplio $y$, por lo mismo, pretende, sin perder su sentido didáctico, ser accesible, ágil y despertar el interés por conocer temas mexicanos de relevancia contemporánea "con la participación, por un lado, de quienes generan el conocimiento de los hechos sociales, y por otro, de quienes dominan el lenguaje audiovisual, pretendiendo así obtener documentales profundos y entretenidos en los que el tedio no sea sinónimo de conocimiento" (Diseño de la serie, 1999). Originalmente se había convenido en hacer la serie completa en coproducción con TV UNAM, pero ello no fue posible debido al cierre de la Universidad por más de un año; sin embargo, se ha mantenido la idea de trabajar en coproducción, así como otros planteamientos originales en la concepción de la serie como proyecto experimental: tener un realizador diferente para cada programa en el ánimo de presentar propuestas diversas de lenguajes filmicos adecuados al tema eligiendo 


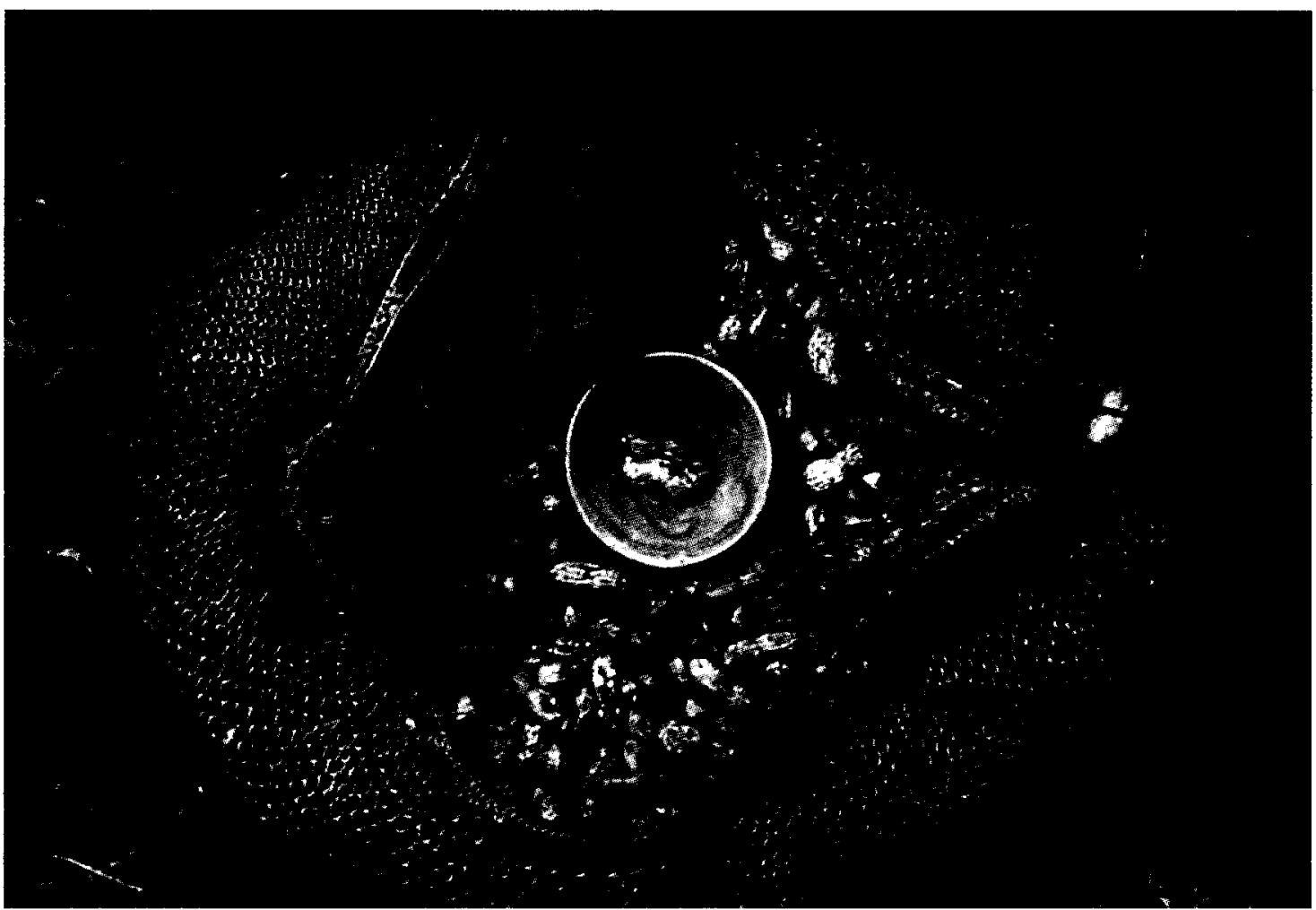

Chiapas; Agustín Estrada

realizadores sensibles al mismo, incluir música original que acompañe la historia filmada y dejar la parte narrativa oral a cargo del responsable de la investigación en que se basa cada programa, quedando a mi cargo la selección de los temas, la perspectiva académica, el tratamiento de los contenidos del video, las entrevistas y algunas veces, la producción. Cada realización me ha puesto frente a problemas, discusiones y dudas de todo tipo en el terreno teórico y metodológico del quehacer de los antropólogos, del lenguaje cinematográfico y hasta de la magia que parece acompañar algunos procesos de investigación en México. La interrogante sobre la que reflexiono continuamente desde que hicimos el primer programa tiene que ver con el terreno que piso dentro de la amplia gama del cine que podemos llamar documental. ¿¿Se está produciendo una obra de cine que respeta la veracidad de la investigación original y, en ese sentido, es un documento fidedigno? Mi trabajo de difusión ¿es más el de la adaptación literaria que el de actividad científica? Ésas y otras preguntas nacen porque en el proceso de hacer el guión y más en la edición, se han mutilado testimonios previos, he reinterpretado otros, he añadido otros, he trastocado los tiempos y he sido parte de una nueva creación. En el proceso he tenido además, roces con los realizadores y con los investigadores; con unos porque a veces "inventan" demasiado, con otros porque quisieran que el programa en video fuera un libro con ilustraciones que diga todo lo que han investigado.

\section{EL ASUNTO DE "LA VERDAD" EN LOS ORÍGENES DEL CINE EN MÉXICO}

En los orígenes del cine, la noción de "verdad" está en la base de su legitimidad como medio de registro. El uso del cine, que en México fue pionero (aunque de esto poco 
se conozca) como medio con la capacidad de recoger la realidad sensible en su movimiento "real" tiene una larga historia como auxiliar en la investigación, apoyo didáctico y difusor de conocimientos. Pensando en la antropología, alguna vez Guillermo Bonfil dijo que un archivo de imágenes pasadas posee la certidumbre de que la imagen es fiel " $y$ no ha sido adulterada por una memoria imprecisa" en clara alusión a lo que hoy llamamos historia oral, y también que "la misión del antropólogo-cineasta consiste en traducir la verdad científica al lenguaje cinematográfico para hacerla comprensible a un público más amplio".

Con el gusto que tengo por saltarme tiempos y hacer flash-backs, quiero comparar esta apreciación del querido G. Bonfil con lo que el fino investigador del cine en México, Aurelio de los Reyes, descubrió que dijeron los intelectuales mexicanos de la época porfiriana cuando, sorprendidos por la invención del cinematógrafo, empezaron a discurrir sobre sus virtudes y posibles vicios.

El cine llegó a México en 1896 y se le consideró como una prueba "del progreso del siglo", según dijeron los reportajes, aunque también fue descalificado como muestra de "vulgarización científica" cuando se fue convirtiendo en diversión popular. ${ }^{2}$ En el año de 1900 se dijo también que, aplicado a la educación, el cine brindaba ventajas didácticas pues "aislaba al sujeto, con lo que disminuía las posibilidades de distracción y aumentaba el nivel de asimilación". Los círculos literarios y científicos porfirianos estaban complacidos con el invento "porque no los podía engañar"; al cinematógrafo se le creía incapaz de mentir. Una de las conclusiones de la investigación es que los filmes nacionales de la época investigada (1896-1900) "se podían tipificar por su apego en mostrar la realidad inmediata, no importaba el argumento, querían solamente enseñar la verdad de los hechos".3

Aunque la mayoría, si no toda, la crónica que se ha hecho sobre el cine antropológico y documental desconoce

${ }^{1}$ Bonfil Batalla, Guillermo "Notas sobre el cine documental en la antropologia", en Desacatos, 1, CIESAS, México, pp. 187-193 [artículo originalmente publicado en 1967].

2 De los Reyes, Aurelio, Los orígenes del cine en México (1896-1900),

Lecturas Mexicanas, 61, FCE-SEP Cultura, México, 1984, pp. 40, 41, 50.

${ }^{3}$ Idem., pp. 22-23, 56, 103, 104.

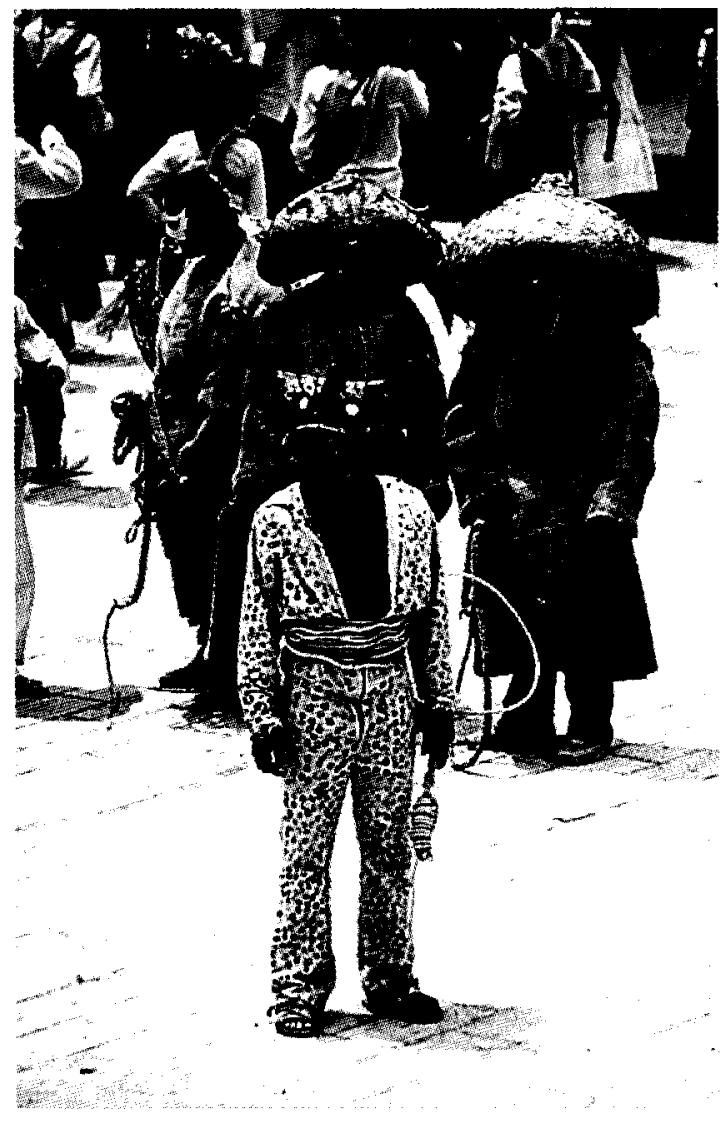

Acatlán, Guerrero; Agustín Estrada

y por tanto omite lo realizado en países no sajones - a menos, claro, que los productos filmicos hayan sido realizados por personajes de sus países-, hay que tener presente que en México uno de los fundadores de la antropología mexicana, don Manuel Gamio, usó al cine en varias formas en una época tan temprana como la etapa comprendida entre 1917 y 1925, marcada por el inicio de sus excavaciones en el valle de Teotihuacan y su renuncia a la subsecretaría de Educación Pública durante el primer semestre del gobierno de Calles. Aurelio de los Reyes, en otra de sus investigaciones, nos dice que a pesar de que las películas no han sido encontradas y sólo se conocen fotos de algunas tomas, ${ }^{4}$ Gamio mandó filmar el

${ }^{4}$ De los Reyes, Aurelio, Manuel Gamio y el cine, UNAM, México, 1991. 
proceso de las excavaciones arqueológicas en Teotihuacan, algunas costumbres de los habitantes de la región como danzas, cantos y el trabajo de las comadronas en un parto, así como las ruinas arqueológicas y otros sitios en Yucatán. De ese modo, "el caso de Manuel Gamio es excepcional en la historia del cine mexicano de la etapa muda, puesto que usó al cine como documental científico en apoyo a la investigación", aunque antes que él y también en México, un médico había usado ese medio como apoyo didáctico filmando operaciones quirúrgicas.

Tan interesante como resulta saber de este uso pionero del cine en México por la antropología, es conocer la manera en que los intelectuales mexicanos se expresaron del cinematógrafo como un medio que, al lado del fonógrafo, era capaz de captar fielmente la realidad y se prestaba para conservar la memoria. Las visiones nacidas en el porfiriato prefiguran tendencias posteriores en las concepciones de la historia y su registro, pero también en las ideas de lo que después conoceríamos como cine etnográfico. ${ }^{5}$ Dice también Aurelio de los Reyes, que para Amado Nervo, nuestro consagrado poeta, la historia era la "verdad" de los grandes hechos y el desfile de personajes notables (1898), mientras que para José Juan Tablada (1896), la historia la componían los pequeños hechos de la vida ordinaria. Casi las mismas palabras que usaríamos hoy para hablar por un lado de "historia heroica" y por otro de "historia social" o "historia popular". Cualquiera que fuera la orientación seguida para la construcción de la historia, el tono de los tiempos originales del cine en México lo reflejó una nota del periódico $E l$ Nacional en 1896, que subrayó las virtudes del cinematógrafo para el registro histórico: "Con un aparato así, se hará la historia y nuestros postreros verán vivos y palpitantes los episodios más notables de las naciones, suprimiéndose el libro... por inútil..."6

\footnotetext{
${ }^{5}$ Óscar Menéndez, antropólogo-cineasta mexicano, dice que el primer documental filmado en México es de 1897; el caso es que la tradición del cine documental y antropológico es antigua y llega a nuestros días aunque con muchos altibajos debidos a la falta de patrocinio. Sin embargo, hay un proyecto del Instituto Nacional Indigenista, el Archivo Etnográfico Audiovisual, creado en 1972, que tiene un gran acervo, mucho de gran calidad y poco usado, sobre las fiestas y modos de vida de la población indígena mexicana.

6 De los Reyes, Aurelio, 1991, pp. 111-112.
}

En los más de cien años que pasaron desde esta profecía incumplida, México ha pasado por transformaciones profundas de las relaciones sociales y de las formas de producir, consumir, mirar y aprender como producto de las formas de vida industriales y urbanas; los intelectuales volvieron a escribir epitafios para los libros cuando aparecieron sucesivamente la televisión, las computadoras y los discos compactos, sólo que añadieron al cine en la lista de medios agonizantes. Pero ahí siguen los libros y ahí sigue el cine, como también prevalece la idea de que cine y verdad son equivalentes, que coexiste con la idea contraria, que descalifica al cine como vulgarizador de la ciencia.

\section{VERACIDADY FIDELIDAD EN LAANTROPOLOGIAA}

En la discusión antropológica sobre el tema de la veracidad, fidelidad y, por tanto, autenticidad en los registros sobre los estilos de vida de los pueblos "sin historia", "ágrafos", "primitivos" o, simplemente "exóticos", se han escrito muchas páginas criticando la audacia de algunos que sin hablar un idioma aborigen toman como válidas las traducciones de sus intérpretes nativos sobre las que basan todo un aparato explicativo; o la falsificación que resulta de mutilar un testimonio oral grabado en cinta magnetofónica cuando se le "edita", o la toma fotográfica que privilegia un encuadre estético por sobre el supuesto dato etnográfico, o la presunción de creer que la memoria es infalible o que el registro gráfico no es confiable porque está fuera de contexto. Me parece que la crítica se ha mantenido en la misma lógica de lo criticado, pues la molestia nace por la supuesta traición a la verdad, la fidelidad y la autenticidad. Veamos esto un poco más despacio.

En la antropología hay una tendencia fuerte a sobrevalorar el registro de tipo directo - cinematográfico, magnetofónico, fotográfico, escrito - del testimonio de un informante esclarecido (o "clave", en la jerga profesional) como garantía de obtener informaciones verdaderas. Cuando registramos con medios audiovisuales, ¿es porque pensamos que sólo así estamos más cerca de la realidad? En una respuesta de sentido común diríamos 
que efectivamente esa es la voz del entrevistado y eso es lo que dijo; también es su cara, su ropa y sus movimientos, por lo tanto, hemos logrado reproducir lo real-sensible. Pero dejando ese ámbito, diriamos que, en efecto, parece él, pero, ¿es él? ¿̇ es en todos los casos mi concepción de él? (o de quien empuñe la pluma, teclee la máquina, emplace la cámara o apriete el botón de grabar) En una respuesta más apegada al proceso de conocimiento científico tendríamos que decir que una cosa es el fenómeno que grabamos y vemos, y otra la explicación que daremos una vez que hagamos acopio de la información disponible y procedamos a organizarla y analizarla; sin teoría que guíe el análisis (y antes, la recolección) de la información obtenida en el campo, difícilmente podrá haber entendimiento de la situación; sin claridad de los códigos culturales diferentes que intervienen en una entrevista o encuentro entre investigador y sus sujetos de estudio que originan distintas percepciones, no puede haber una ubicación correcta del investigador. El conocimiento previo y el tratamiento profundo de las situaciones a filmar están en la base de un registro veraz y no superficial o manipulado.

Creo que muchos podemos decir con Clifford Geertz que el etnógrafo no percibe, y es imposible que perciba, lo mismo que sus informantes (recordemos que los antropólogos sajones por lo general estudian a sus "contemporáneos primitivos").

Lo que él percibe, y de una manera no muy segura, es lo que ellos usan para percibir "con" o "por medio de" o "a través de" [...] cualquiera que sea el sentido preciso o semipreciso que alcance a formular el antropólogo con respecto a lo que son realmente sus informantes, ese conocimiento no proviene ciertamente de la experiencia de la aceptación en sí [del investigador por las personas que estudia], pues ésta forma parte de la biografía del investigador, no de los sujetos de estudio. El conocimiento proviene estrictamente de la habilidad para interpretar sus modos de expresión, de lo que podrían llamarse sus sistemas simbólicos, lo cual está condicionado por la aceptación. Comprender la forma y presión de [... la vida interna de los nativos es más parecido a entender un proverbio, darse por aludido, entender un chiste $[\ldots]$ que a comulgar. (1991: 103, 110).

Si estamos de acuerdo, los etnógrafos resultamos intermediarios culturales que vamos por la vida tratando de entender los comportamientos de otros, interpretando y tratando de hacer inteligible una forma de vida, mirándola como experiencia humana y que nuestra etnografía es buena en la medida en que nuestra interpretación - con el uso de fuentes orales, escritas y/o visuales- no traicione los valores entendidos de la cultura bajo estudio.

Me parece que de la literatura que conozco, los que hacen cine documental están más cerca de estas posiciones que los que hacen el llamado "cine etnográfico", al menos en los países sajones. Veamos.

\section{CINE ETNOGRÁFICOY CINE ANTROPOLÓGICO}

Dijo Timothy Asch: "La información en que descansa el trabajo antropológico procede del registro etnográfico. En los inicios la información era registrada por escrito, luego en grabadoras y fotos. Se abrieron más opciones con la aparición de las cámaras en $16 \mathrm{~mm}$ y super 8 y los equipos portátiles de video... La tecnología audiovisual es más efectiva para la investigación cuando se busca la visión repetida de eventos únicos... Las películas etnográficas son al antropólogo social lo que las grabaciones de campo a los lingüistas." 7 Otro autor, Asen Balikci, que trabajó en Canadá, ha escrito que el ejemplo de los antropólogos Boas y Mead, el primero estudiando a los esquimales y los indios de la costa occidental de Estados Unidos y la segunda a los "primitivos" habitantes de Samoa, motivaron a varias generaciones de antropólogos a estudiar comunidades pequeñas y aisladas y a llevar un registro escrito sobre sus modos de vida con el doble objetivo de llevar el registro de generaciones sucesivas en una comunidad local para reconocer la continuidad cultural que los vincula con sus antepasados y el de permitir

\footnotetext{
${ }^{7}$ Asch, Timothy, "Collaboration in Ethnographic Filmmaking", en Rollwagen, Jack R. (ed.), 1996, p. 2 (trad. de VN). Este antropólogo, ya fallecido, se vio envuelto en una discusión sobre ética profesional cuando se le acusó en una publicación de haber incurrido en conducta no ética cuando filmó dos documentales en Brasil (1968 y 1975). Fue exculpado después de analizar su obra, por la Society of Visual Anthropology, de la que formó parte, y puesta a salvo su reputación en noviembre del año 2000.
} 
que los científicos y el público en general descubrieran la originalidad intrínseca y el funcionamiento específico de la cultura local, especialmente cuando es exótica. Para este autor, la filmación de películas etnográficas no sustituye el registro y la descripción escrita, pero es un complemento importante por su potencial de acercarse a la verdad etnográfica, lo cual puede lograr el etnógrafo al seleccionar y vincular

los elementos visuales de una cultura con el propósito último de construir una composición más amplia y comprensiva. Tanto en las secuencias como en la composición final, el etnógrafo tiene la responsabilidad moral de registrar e interpretar los estilos de vida locales con un máximo de fidelidad empírica y lo más cercanamente posible al modelo descriptivo. A eso le llamamos "la verdad" en el cine etnográfico. Al cine etnográfico lo define como una filmación en vivo, sin escenografía, guiones, sets prearreglados ni actores profesionales donde se da la preferencia a tomas largas desde una distancia social "normal", cubriendo largas secuencias de interacciones espontáneas y de principio a fin ilustrando los cuerpos completos. Esta estrategia de grabación distingue al género etnográfico del estilo documental que es más estructurado, que acepta jugar con los ángulos y efectos visuales y fuerza al realizador a pensar constantemente en las tijeras de la edición En un sentido, el realizador etnográfico está preocupado sólo con los contenidos, mientras que el documentalista está obligado a pensar también en la forma, lo cual es una diferencia básica. ${ }^{8}$

Otro acercamiento algo más radical, del mismo género que yo diría "empiricista", es el de John Collier Jr., quien dice que el cine etnográfico separa el registro cultural de las narrativas dramática y artística (que es lo que hace el documental); la etnografía observa las esencias de la cultura de acuerdo con el valor que los nativos o practicantes de la cultura le dan a sus actos. Esto es, en otras palabras, el inside view (o mirada desde dentro) que para el cine etnográfico es lo auténtico y que alcanza su máxima expresión cuando se le da la cámara al nativo. ${ }^{9}$

${ }^{8}$ Balikci, Asen, "Anthropologists and Ethnographic Filmmaking", en Rollwagen, Jack R. (ed.), op. cit., p. 32 y 33-34. Trad. libre del inglés de V. Novelo.

${ }^{9}$ Collier, John Ir., "Visual Anthropology and the Future of Ethnographic Film", en Rollwagen, Jack R., op. cit., pp. 89, 91.

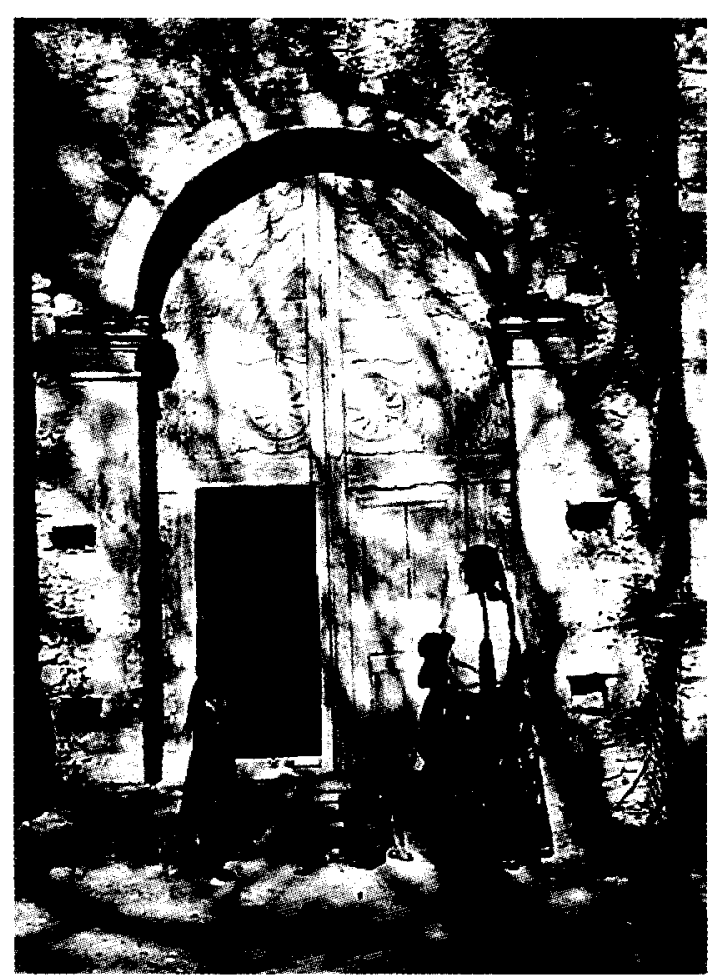

Zitlala, Guerrero; Agustín Estrada

Me parece que el problema de estos enfoques o posturas es que parten de la idea de una ciencia como resultado de la descripción de lo inmediatamente visible, que suponen es la "realidad", a través del registro "objetivo" de hechos. En esta aproximación al cine la teoría no existe o está subordinada a la recopilación de datos. Como bien dice un antropólogo-cineasta más crítico, J. Rollwagen, "la suposición de que lo que se filma es la realidad y el público va a entender lo que ve por su evidencia, es falso. ¿Cómo un público perteneciente a un sistema cultural va a entender algo de otro sistema cultural? La antropología ha demostrado [...] que la naturaleza de los sistemas culturales no puede ser evidente a los no-participantes [...] (y ha) contribuido al entendimiento del comportamiento humano con un gran cuerpo de observaciones (etnografía), un cuerpo de teoría (etnología) surgido del análisis comparativo de culturas que interpreta las observaciones". Añade que el cine antropológico, con otra posición que el cine etnográfico, "usa el trabajo de campo 


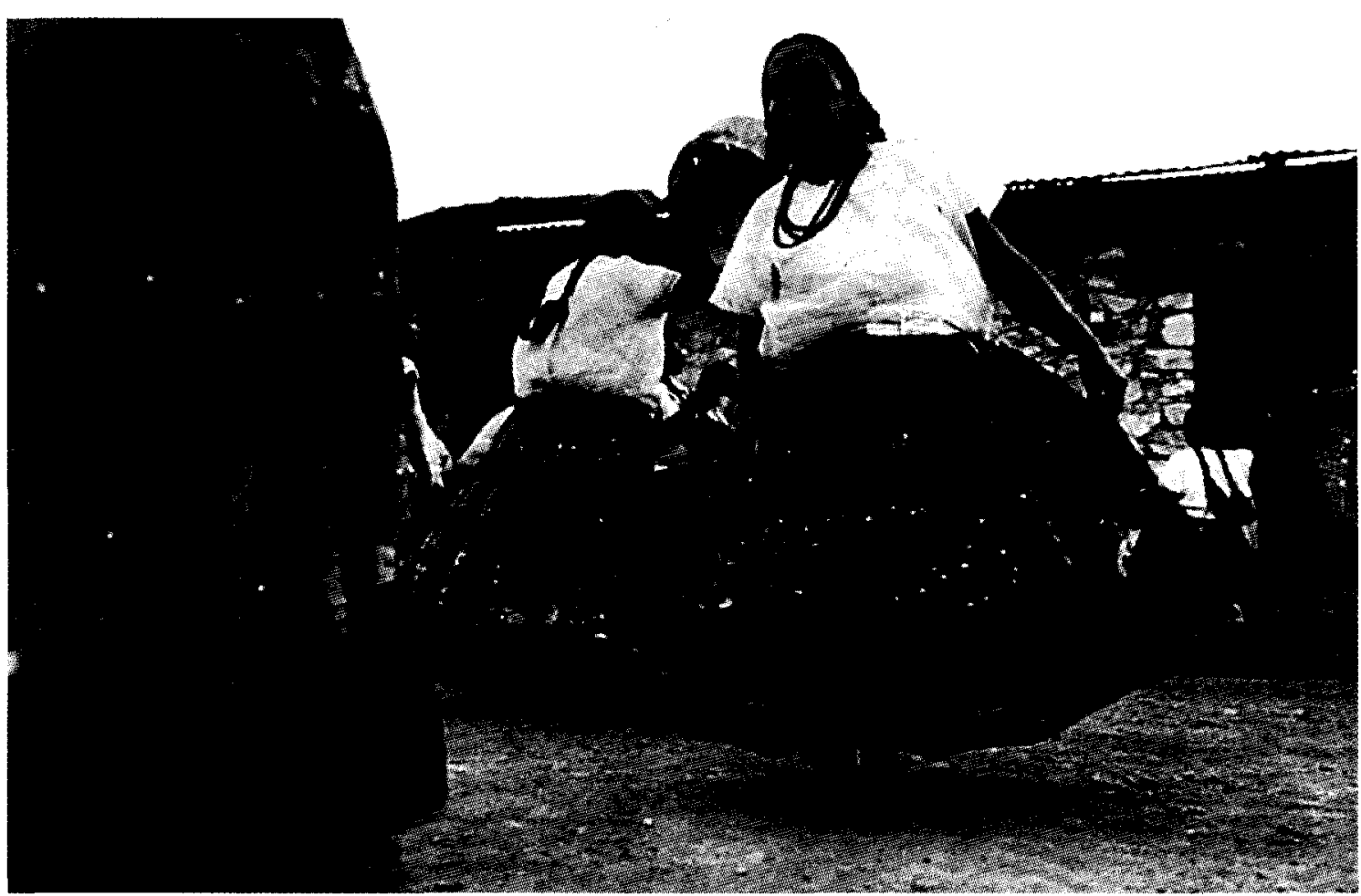

Zitlala, Guerrero; Agustín Estrada

intensivo con métodos comparativos y la explicitación del marco teórico dentro del que se interpreta el tema a filmar. Los que hacen cine etnográfico dicen que el registro es un ejercicio empírico mientras que el que hace cine antropológico reconoce que la filmación, como el trabajo de investigación, está condicionado por la habilidad del antropólogo para concebir su trabajo en los términos de la teoría antropológica. La teoría permea toda la investigación: la fase de concepción del proyecto, la definición del tema, el registro de las observaciones, el proceso de análisis y la preparación de los productos finales..."10

Hay otra crítica posible a las posiciones que creen firmemente en que el registro directo de un evento, en vivo, sin cortes, sin escenografía ni actores garantiza su autenticidad. En la historia de una filmación en México sobre el culto al Niño Fidencio, los autores relatan cómo se llevó ${ }^{10}$ Rollwagen, Jack Jr., "The role of Anthropological Theory in Eth-
nographic Filmaking", en Rollwagen, op. cit., pp. 288, 293-294 y 331. a cabo un ritual en el que supuestamente la protagonista se encontraba poseída por el espíritu del poder divino $y$, por tanto, en trance. Cuando comenzó la filmación, la "poseída" se acercó a los antropólogos para preguntarles, con voz normal, si las escenas estaban acordes con lo que querían filmar. Los autores declaran que ese fue un problema durante toda la filmación y lo explican en términos de que la gente de la región "está expuesta a la TV y a las películas comerciales, por lo que conocen la mecánica de la producción filmica”. Ellos confirmaron sus sospechas sobre la profundidad de los "trances", pero aseguran que la distorsión de la realidad la hacen los participantes y no los que filman. Yo concluyo que los antropólogos filmaron un registro auténticamente falso, lo cual no parece importarles en términos de su muy particular cine etnográfico. $^{11}$

11 Olson, John L., "Filming the Fidencistas: the Making of We believe in Niño Fidencio", en Rollwagen, Jack R., op. cit., pp. 261 y 264. 


\section{CINE DOCUMENTAL}

Pasando al campo de quienes hacen cine documental, parece ser que fue John Grierson, del National Film Board de Canadá, quien en 1932 fue el primero en usar el término documental cuando reseñó la película Moana (1926) de Robert Flaherty, y dijo que la película, siendo una suma visual de acontecimientos de la vida cotidiana de un joven polinesio y su familia, tenía valor documental. ${ }^{2}$ Él mismo ha dicho también que el triunfo de la capacidad del cine para la observación de la vida puede ser explotado en una forma artística, nueva y vital, abriendo las pantallas al mundo real donde el documental fotografiará las escenas en vivo y las historias vivas; "el escoger como medio el documental es una decisión grave, como la de la poesía en lugar de la ficción".13

Los cineastas que se han dedicado a filmar grupos y situaciones de culturas no occidentales hablan del documental como la filmación de una vida cotidiana que se caracteriza porque tratan con eventos y personas reales, en oposición a las escenas teatrales de caracteres imaginarios o las historias de ficción hechas en los estudios de cine. Para Robert Edmonds, el documental es inmediatamente antropología filmada: "La realidad o actualidad de las relaciones del hombre con su trabajo, ambiente y su sociedad." Sin embargo, la filmación de esa realidad es también un acto creativo: "En la elaboración de una película, el realizador tiene una cantidad de elementos estéticos que extraer, aunque sea un filme documental donde no tenga control de lo local, del escenario, modas, reparto $y$ hasta trama [...] la estética es lo que enfatizamos o arreglamos (tiempo, espacio, colores y elementos similares) que intensifican los sentimientos cuando se presenta la obra."14

$\mathrm{Al}$ reconocer la inclusión de la creatividad en la filmación de situaciones de vida, el documentalista, en

\footnotetext{
12 Edmonds, Robert, "Documental, antropología filmada", en CUEC. Material didáctico de uso interno, México, $\mathrm{s} / \mathrm{f}$ (ca. principios de los años ochenta), trad. del inglés de José Rovirosa, pp. 1-94.

${ }^{13}$ Grierson, John, "Principios del documental", tomado del libro Grierson on Documentary, en CUEC..., op. cit., pp. 98-120.

14 Robert Edmonds, op. cit., pp. 48 y 57.
}

comparación con el cineasta-etnógrafo tiene claridad en que la filmación implica decisiones, selecciones y puntos de vista:

Es imposible hacer una película sin seleccionar por lo menos algunos elementos, los lugares donde se pondrá la cámara, las cosas que hay que incluir en el shot y las cosas que hay que sacar; la forma de corte de una toma a la otra; la longitud que se debe dar a cada escena cuando se está haciendo el corte, además de cumplir con otras exigencias cinematográficas... la selección y la distorsión son inevitables en la manufactura de una película... seleccionamos aquellos o estos aspectos de nuestro material con el ánimo de que puedan ser más débiles o más poderosos para demostrar cualquier cosa... o por enfatizar algunos aspectos y minimizar otros, estamos abstrayendo de la totalidad de la realidad aquellas partes que satisfacen nuestros propósitos. En esta forma hemos revelado un lenguaje simbólico. ${ }^{15}$

Para el documentalista mexicano Eduardo Maldonado, muy cercano al cine antropológico, además de la necesaria documentación previa y la reflexión que la investigación filmada va demandando, la emoción y la intuición del realizador y su equipo es una parte esencial en el rodaje y está presente también en la selección y tratamiento del tema, así como en la apertura para "ver" cosas no anticipadas. ${ }^{16}$

\footnotetext{
15 Idem, pp. 92-93.

${ }^{16}$ En México, fuera de las películas documentales hechas con el patrocinio del Archivo Etnográfico Audiovisual del INI, tanto de antropólogos-cineastas como de cineastas-investigadores que han producido un riquísimo acervo de alta calidad, el patrimonio fílmico nacional en esta rama no ha tenido un incremento notable desde los años ochenta; hay producciones aisladas de cineastas independientes o patrocinados por instituciones de educación superior como el CCC y la UNAM con su Filmoteca y el CUEC. Donde sí ha habido crecimiento es en la producción de videos, tanto de documentalistas independientes como dentro de las universidades; podemos citar a la Universidad Autónoma Metropolitana Iztapalapa, donde trabaja Scott Robinson, antropólogo-cineasta; la Universidad de Colima, con su centro de video didáctico; el ITESO de Guadalajara, con un grupo de jóvenes artistas videoastas muy interesantes y creativos, como Paula Silva y Andrés Villa Aldaco; el Instituto Mora, con su proyecto filmado de historia oral; TV UNAM, asi como algunas producciones del Canal 11 del IPN y el canal 22 del Conaculta. En el $4^{\circ}$ Festival de Cine de la Ciudad de México, año 2000 , se presentaron quince documentales en video y cine de $16 \mathrm{~mm}$ (Itala Schmelz, comunicación personal). En el segundo festival regional "Cine-Video-Sociedad", realizado en Mérida, Yucatán (abril 8-15 de 2000) se presentaron 55 videos a concurso, de los cuales 28 eran documentales. El desarrollo del video documental ha estado
} 
Desde esta perspectiva, en las experiencias de los registros visuales, las imágenes obtenidas son también un reflejo, diría John Mraz (1997: 47), o una interpretación, diríamos otros, de cómo perciben el mundo los que están tras las cámaras, los que construyen un producto filmado, los que dicen que retratan la vida de otros. Se relativiza así la noción de "realidad" que captan los sentidos de los antropólogos puesto que es tamizada por sus habilidades científicas como intérpretes, por su capacidad de lograr aceptación y establecer comunicación con los sujetos de la filmación; el registro que se obtendrá desde el punto de vista de su validez está en íntima relación con la calidad de la interpretación. Queda de cualquier modo latente el asunto de cómo percibe el público el producto cinematográfico; ahí hay otra interpretación posible y también puede haber otra percepción y ese es un problema de comunicación que se debe tener presente.

\section{LA COLABORACIÓN ENTRE ANTROPÓLOGOS, DIRECTORES Y PRODUCTORES}

En mi trabajo, parto de una investigación terminada y publicada; selecciono las tesis fundamentales pensando en sus potencialidades como narración visual, entrevisto al autor para elaborar conjuntamente el esquema de los contenidos y conocer la perspectiva y el método de trabajo que usó. Me asesora en la selección de locaciones y de personas e instituciones donde es posible obtener tanto entrevistas como documentos adicionales, y de estos primeros encuentros surge el boceto del guión que será

relacionado con la incursión en la televisión cultural y los programas noticiosos de televisión y como derivación del cine-testimonial. En el video documental se recupera la aproximación antropológica del testigo ocular que registra situaciones sociales y eventos de la vida de los desposeídos, los marginados y las poblaciones indígenas. Con la irrupción del movimiento zapatista en Chiapas y de las luchas políticas por la democracia, el número de producciones de "denuncia" creció en forma importante; Arturo Lomeli, antropólogo y videoasta radicado en Chiapas, anota al Canal 6 de Julio, el Colectivo Perfil Urbano, la primera etapa de Argos y La Guillotina como los colectivos más importantes. También en Chiapas destaca el trabajo independiente de Carlos Martínez Suárez. luego precisado con el realizador del programa, un director de cine o video, con quien también discuto y apruebo (o al menos ésa es mi pretensión) el tipo de discurso, ritmo y "mirada" que tendrá el filme. De este modo, a los testimonios que el investigador original recogió en el campo, el video añadirá otros en su proceso de filmación, a menudo con los mismos informantes originales; entre éstos, figura en forma importante una entrevista filmada al autor(a) de la investigación, que servirá, con su propia voz, como la narración central del video con las tesis que manejó. A esto hay que añadir que el realizador del video aporta su imaginación creadora y sus habilidades en la dirección y/o manejo directo de la cámara, la selección y longitud de las tomas, la edición y la presentación final. El programa así es resultado de un trabajo creativo en el que converge la multidisciplina, la superposición de tiempos testimoniales y un nuevo lenguaje audiovisual.

En el caso de la serie "Antropo-visiones", la colaboración entre diferentes especialistas es así un requisito y una necesidad del trabajo. Pero no ha sido nada fácil. Como ya dije, parto de una investigación terminada, es decir, donde el proceso de construir una explicación de un determinado hecho social ya fue hecho siguiendo todos los pasos de una investigación antropológica que incluyó, centralmente, el trabajo de campo. Para hacer mi proyecto de programa debo documentarme, en este caso, leer los productos de la investigación que me interesa, sintetizar sus tesis y sus aportes y seleccionar los hechos y procesos que se van a narrar en el video. Con el investigador sostengo varias entrevistas, primero para convencerlo de las virtudes de la difusión de su investigación entre un público amplio; luego le propongo las partes susceptibles de ser filmadas y los énfasis posibles, siempre con respeto a sus tesis. Le hablo de la necesidad de su asesoría y le explico que en el proceso de filmación puede generarse nueva información, aun con sus propios informantes como entrevistados, la cual podrá incluirse dentro del esquema general, si cabe, o bien como una nueva hipótesis de trabajo. También le informo sobre el tratamiento fílmico en cuanto a ciertos acentos de la investigación, de entrevistas que pienso se deben hacer a otros especialistas y protagonistas del tema buscando 
a veces un contrapunteo, a veces una comparación, otras, la perspectiva histórica y la ubicación en un contexto mayor, o bien un nuevo testimonio que profundice $o$ que inyecte emociones a la narración. En este sentido, la serie puede tener alguna semejanza con el cine antropológico como herramienta de investigación, porque está generando información testimonial fresca y nueva en un tiempo, y a veces un contexto, diferente al original. Generalmente no se suscitan problemas en esta parte del proyecto; quizá sólo las dudas que tiene cualquier antropólogo sobre el tratamiento que recibirán "sus" informantes, el cuidado con que se les debe tratar, los temas que hay que evitar con ellos, en fin, exigencias propias del celo y la ética profesional que busca mantener las buenas relaciones que ha cultivado durante algún tiempo y de los cuales ha dependido su aceptacióı. Hasta ahora no ha habido discusión teórica o metodológica entre los investigadores y la directora de la serie; los temas hablados son predominantemente prácticos.

La segunda fase comprende varias conversaciones con el realizador y el productor (cuando ha habido) para transmitirles de la mejor y más clara manera posible cuáles serán sus tareas, cuál es el tema del programa, los contenidos aproximados con sus énfasis, el programa de entrevistas, las posibles locaciones, la localización de iconografía o locaciones alternas y otra información que requieran (que en un par de ocasiones consistió en explicar las diferencias entre antropología y folklore). Del realizador, poseedor del oficio de filmar, yo espero una propuesta del estilo que utilizará (el tratamiento visual),

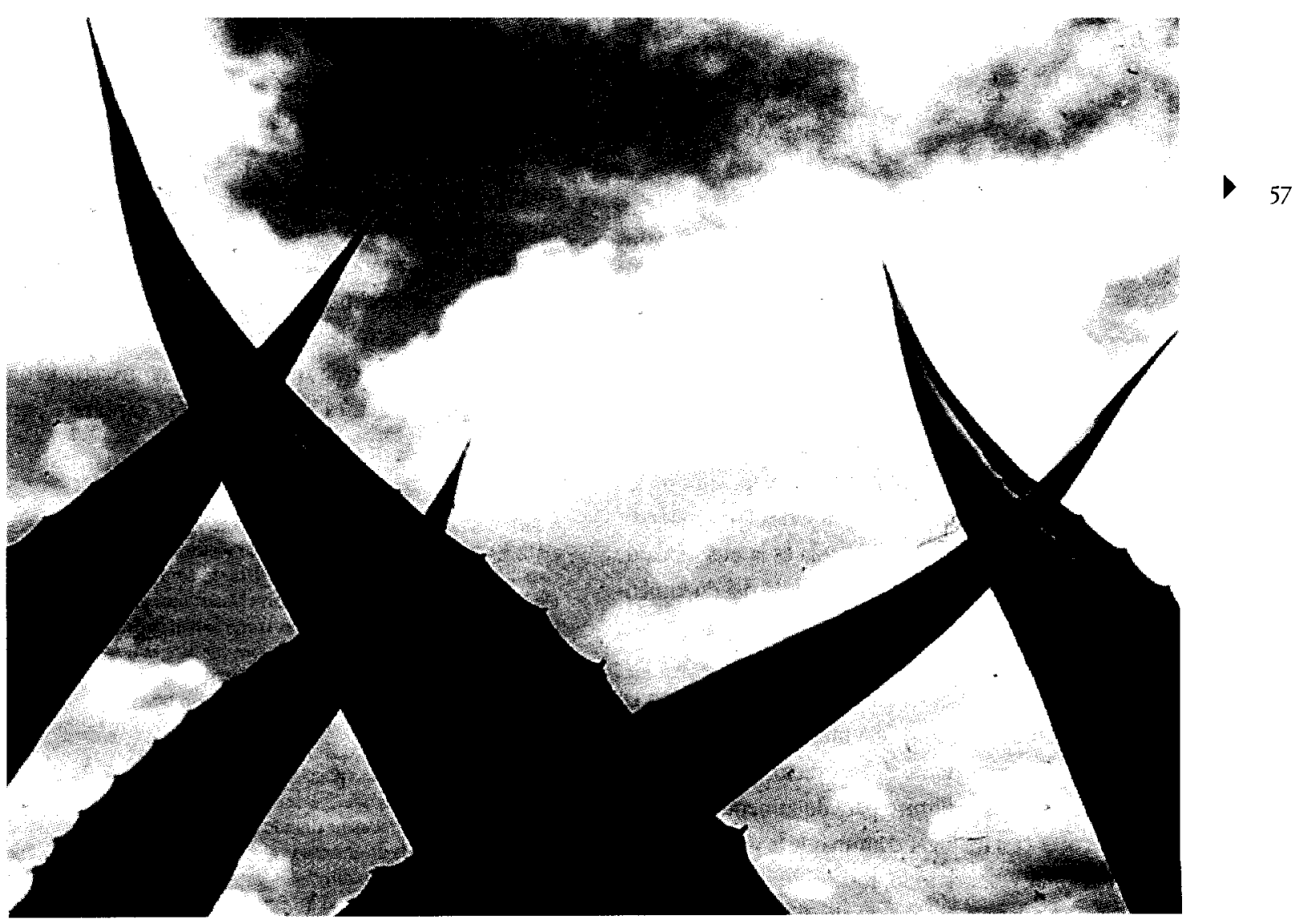

Valle del Mezquital, Hidalgo; Agustín Estrada 


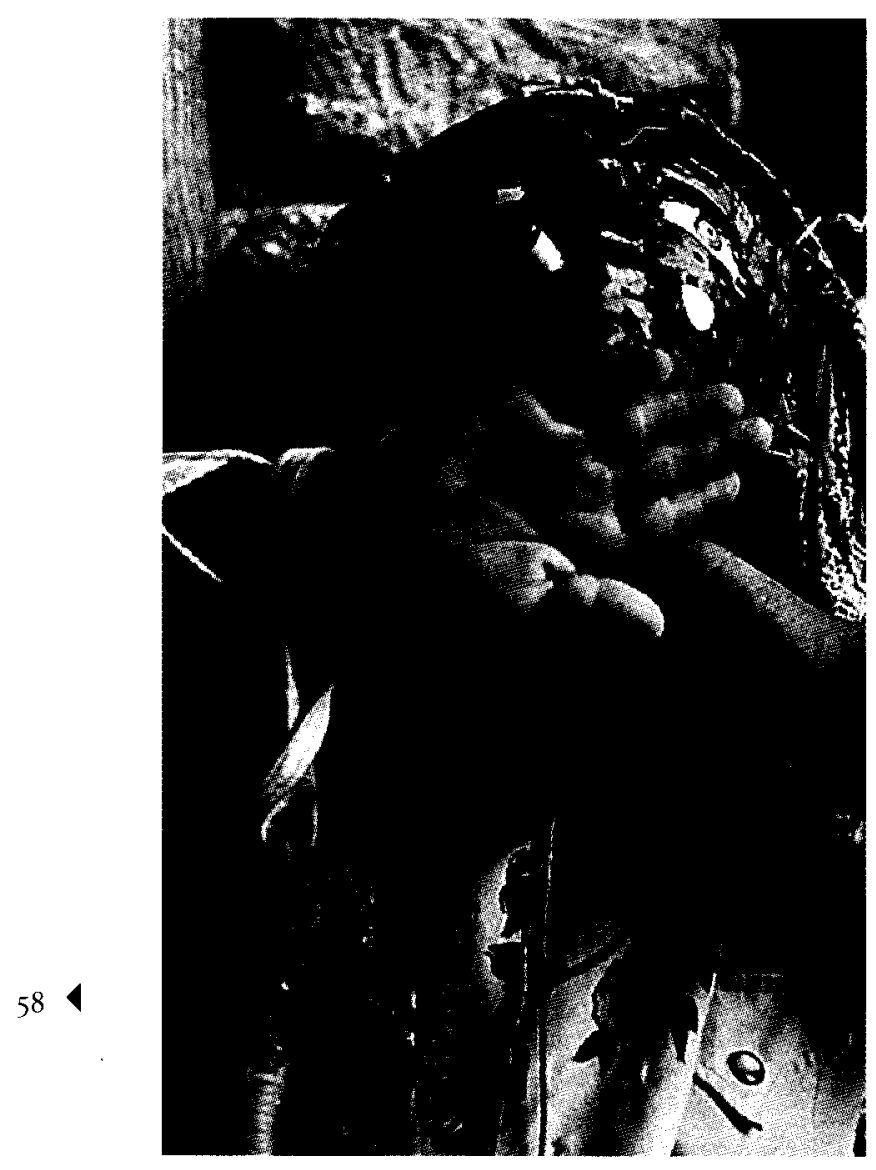

Acatlán, Guerrero; Agustín Estrada

el plan de filmación y la apertura suficiente para discutir en conjunto el concepto total del proyecto. Uno de los objetivos - experimentales- de la serie al proponer directores diferentes para cada película es la búsqueda de tratamientos novedosos dentro del estilo del documental, con una agilidad acorde al tema y los tiempos y de acuerdo con la tecnología más avanzada con la que podamos contar, que mantenga el interés del público en general durante 27 minutos. La música original es también una parte importante del proyecto en la búsqueda de un nuevo lenguaje fílmico para documentales hechos en México; es casi un lugar común que la producción fílmica nacional $y$, sobre todo, los programas que tienen relación con temas de la antropología, tengan una música de fondo dizque prehispánica - tamborcitos y flautitas - o bien los gastadísimos segmentos de la música sinfónica de autores mexicanos que incluyen aires populares como música de mariachi o de huapango.

La tercera fase, la salida al campo a filmar, es la fase más creativa, camaraderil y amable de todo el proceso, por lo menos hasta ahora. Sin embargo, pueden presentarse algunos problemas de comunicación entre mi dirección y la del realizador, cuando, por ejemplo, yo propongo algunas locaciones y tomas o cuando no he sido yo quien hace las entrevistas (lo cual a partir del segundo programa considero indispensable) y es hasta la sala (o isla) de edición que me doy cuenta de lo realmente filmado o que el material no resulta del todo aceptable porque expresa sólo el punto de vista del entrevistador y no del plan convenido en el equipo. ${ }^{17}$

La cuarta fase, la posproducción del material, es decir, la construcción de la exposición final que será el programa de 27 minutos, es la más difícil y donde más discusión hay entre la antropóloga (yo) y el realizador, en lo que se refiere a la coherencia, la claridad y la perspectiva de la narración; y entre antropólogos, cuando los investigadores originales observan que el video no cumplió con sus expectativas, pues sólo se desarrolló uno de los posibles temas y no una monografía completa; y entre realizador y productor, generalmente por la falta de cumplimiento del primero en las fechas de entrega.

Como no se trata de una película de investigación propiamente dicha, es decir, donde la cámara es un

\footnotetext{
${ }^{17}$ Lo "no aceptable" a veces tiene razones técnicas, por ejemplo, fotografía y encuadres fallidos o demasiado obscuros, respuestas imprecisas a preguntas mal formuladas, falta de contextos visuales, etc. Desde que estuvo en posproducción el cuarto programa es que veo la necesidad de ponerse de acuerdo, como lo han hecho algunos colegas, con los equipos de filmación sobre cuestiones importantes como el dejar que se muestre y exprese la personalidad del entrevistado o el ambiente de intimidad que puede dar un buen - y cercanoencuadre a la cara del entrevistado. El antropólogo Allan Burns (Universidad de Florida), con quien alterné como maestro en un taller de antropología visual para videoastas indígenas, me decía que a él no le gustaba hacer entrevistas con la gente sentada en una silla, prefiere filmarlos mientras trabajan; cuando entrevista a gente muy mayor, escoge a alguien de la misma edad como entrevistador para lograr una relación de pares. A otros directores les parece más importante tratar de aprehender la personalidad del entrevistado, quien puede estar parado, sentado, trabajando, caminando, descansando, etc., pero en un buen escenario (atractivo, interesante, de contexto).
} 
observador de comportamientos y va acompañando todo el proceso de investigación que puede durar meses o años, y que se interpretará al terminar la filmación, no es necesario que el antropólogo original o la directora de la serie analicen todo el material para plantear una nueva interpretación, aunque para insertar la información nueva que se generó sea necesario decidir su lugar en el discurso general de acuerdo a la "columna vertebral" que es la narración del investigador. Tampoco se trata de una película etnográfica como la entienden los autores que revisamos antes, de manera que no es necesario mantener secuencias largas de eventos completos sin cortes, ya que no es el objetivo del programa hacer registros de archivo para consulta (aunque se guardan los originales - masters - completos para un futuro banco de datos del CIESAS). Sin embargo, la cualidad etnográfica, para el buen observador, está presente en las imágenes y en los lenguajes usados, además de la capacidad de la cámara que puede "ver" más allá del ojo humano, generando así otra información. No es tampoco "cine de autor", entendido como producto de la inspiración y el estilo del realizador, de ahí que deban enfrentarse situaciones incómodas provocadas por las individualidades del realizador o la antropóloga. Como directora de la serie, mi responsabilidad es que el producto filmado tenga una coherencia narrativa en términos de contenidos y de fidelidad a la investigación original en cuanto a sus propuestas de interpretación. La narración está construida en un documento visual que hizo el director fílmico del programa, pero el producto total resulta de un trabajo conjunto directora de la serie-realizador.

De lo que se trata es de presentar en forma visual una serie de imágenes vivas, dispuestas de acuerdo con una orientación teórica y estética, tejidas en conjunto con la narración oral que les da sentido para presentar un hecho social que se trabajó como problema de investigación, que contiene una selección de la información a través del testimonio de sus protagonistas o intérpretes, y cuyas soluciones o mensajes, generalmente abiertos, permitan la reflexión a quien lo ve. De ahí su carácter de documento visual, tejido con un método que involucra información, interpretación y conclusiones narradas en forma dramática y artística; los programas permiten conocer hechos y sus interpretaciones en una manera que, además de ser creíble, sea mirable.

Lo que es definitivo es que el producto que hacemos en cada programa es una nueva creación que añade a la investigación original nuevos valores que también provienen de la "mirada" antropológica; de ahí que si bien cada tema está basado en una investigación terminada, no la reproduce, la vuelve algo distinto, manteniendo la fidelidad al tema investigado. Y de ahí, por tanto, que la serie "Antropo-visiones" puede legítimamente quedar comprendida en el género del video-documental, por su calidad de "observador de la vida", con escenas e historias vivas, pero además porque ha implicado decisiones cinematográficas que, semejante a lo observado por Edmonds, tienen que ver con una elección y una selección de énfasis, de grado de abstracción, de ritmo, de encuadres, de ambientes y sus colores, de voces, de música, de acercamientos y alejamientos, atributos todos ligados a la creatividad y por tanto a la subjetividad.

Al respecto, a veces pienso que vienen muy bien las palabras que escribió Javier Marías a propósito de las potencialidades de la novela frente a los reportajes $u$ otras formas de escribir historias verídicas, cuando dice que a ese género literario se le puede añadir lo posible además de lo cierto, los fracasos además de los hechos, lo descartado y lo que pudo ser, además de lo que fue.

\section{UNA NOTA SOBRE EL CONCEPTO DE “ANTROPOLOGÍA VISUAL”}

Sobre la especialidad de la "antropología visual", existe una sección con ese nombre en la American Anthropological Association, dos revistas en inglés dedicadas al asunto, amén de algunos libros, memorias de congresos y sitios en internet. Los autores de habla inglesa que consulté caracterizan a la antropología visual como un particular modo de registro de conductas humanas para ser usados dentro de la investigación antropológica. El mayor énfasis que encontré se refiere al registro fotográfico y filmado de la comunicación no verbal, al uso de la fotografía fija para que sea interpretada por los informantes y así generar información sobre eventos pasados o 
como materia prima para hacer inventarios culturales (Collier, 1996: 91, 93), o bien como una subdisciplina de la antropología sociocultural que estudia los sistemas visuales y la cultura visible: "la producción y el estudio de fotos fijas, el estudio del arte y la cultura material y la investigación de los gestos, la expresión facial y los aspectos espaciales del comportamiento" (Morphy y Banks, 1999: 2-4). Guillermo Bonfil había escrito con anterioridad sobre las posibilidades que tenía el cine para captar las expresiones de un rostro, los gestos, las muecas y todo el lenguaje facial (1999 [1967]: 189), pero dentro de una concepción amplia del término "visual" que es la orientación que priva entre los antropólogos mexicanos que usan el término, identificándolo con "antropología de la imagen" como complementaria de la "antropología de la palabra", refiriéndose más bien al medio de registro en la investigación y en la presentación de resultados (Salazar Peralta, Ana María (coord.), 1997).

El "nuevo" término puede encuadrarse en la típica búsqueda de tres pies al gato (muy propia de los intelectuales de los países altamente industrializados y superespecializados) cuando los contenidos del nuevo concepto están ya implicados y contenidos en conceptos anteriores y más abarcadores como el de cine documental, etnográfico o antropológico, según su énfasis, estilo, formato y destinatario. Pero bueno, cada quien puede crear el término que guste, siempre y cuando lo explicite.

\section{Referencias}

Asch, Timothy, 1966, "Collaboration in Ethnographic Filmmaking", en Rollwagen, Jack R. (ed.), Anthropological Filmaking, Holanda, pp. 1-29.

Balikei, Asen, 1966, "Anthropologists and Ethnographic Filmmaking", en Rollwagen, Jack R. (ed.), Anthropological Filmmaking, Holanda, pp. 31-45.

Bonfil Batalla, Guillermo, 1999 [1967], "Notas sobre el cine documental en la antropología", en Desacatos, núm. 1, CIESAS, México, pp. 187-193.

Collier, John Jr., 1966, "Visual Anthropology and the future of Ethnographic Film”, en Rollwagen, Jack R. (ed.), Anthropological Filmaking, Holanda, pp. 73-96.

De los Reyes, Aurelio, 1984, Los origenes del cine en México (1896-1900), Lecturas Mexicanas, 61, FCE-Cultura SEP, México.
_- 1991, Manuel Gamio y el cine, Colección de Arte, 45, Coordinación de Humanidades, UNAM, México.

Diseño de una serie de programas documentales en video, coproducidos por el CIESAS y TV UNAM, CIESAS, enero, 1999, ms.

Edmonds, Robert, s/f, "Documental, antropología filmada", en CUEC. Material didáctico de uso interno, $\mathrm{ms}$, (trad. del inglés de José Rovirosa), México, pp. 1-94.

Fernández Repetto, Francisco, 1997, “Una aproximación a la antropología visual para dos proyectos en Yucatán”, en Salazar Peralta, Ana María (coord.), Antropología visual, México, IIA-UNAM, pp. 17-28.

Geertz, Clifford, 1991, "Desde el punto de vista de los nativos, sobre la naturaleza del conocimiento antropológico", en Alteridades, UAM-I, I (1), México, pp. 102-110.

Grierson, John, s/f, "Principios del documental", en CUEC. Material didáctico de uso interno, $\mathrm{ms}$, (trad. del inglés de José Rovirosa), México, pp. 98-120.

Lomelí, Arturo, 2000, Ponencia para el diplomado en antropología visual, s/t, ms, San Cristóbal de las Casas, Chiapas, México.

Meran Barsam, Richard, s/f, "Definición de películas de no ficción", en CUEC. Material didáctico de uso interno, ms, (trad. del inglés de José Rovirosa), México, pp. 121-144.

Morphy Howard y Marcus Banks (eds), 1999 (1a. ed. de 1997), Rethinking Visual Anthropology, Yale University Press, Gran Bretaña.

Mraz, John, 1997, "Querían fotos; algunas inquietudes en torno a la antropología visual", en Salazar Peralta, Ana María (coord.), Antropología visual, UNAM, Instituto de Investigaciones Antropológicas, México, pp. 45-54.

Novelo, Victoria y Eduardo Maldonado, 1997, "Laguna de dos tiempos, una experiencia de investigación filmada", en Salazar Peralta, Ana María (coord.), Antropología visual, UNAM, Instituto de Investigaciones Antropológicas, México, pp. 101-110.

Olson, John L., 1966, "Filming the Fidencistas: The making of We believe in Niño Fidencio", en Rollwagen, Jack R., (ed.), Anthropological Filmaking, Holanda, pp. 259-272.

Rollwagen, Jack R., 1966 (4a. ed.), "The role of Anthropological Theory in Ethnographic Filmmaking", en Rollwagen, Jack R., (ed), Anthropological Filmaking, Hardwood Academic Publishers, Holanda, pp. 287-315.

Video Fogón y campo, 2000, Unidad de Producción Audiovisual y Multimedia, ITESO, Guadalajara, Andrés Villa Aldaco (director).

Video INPUT, 2000, International Public Television Conference, Halifax, Canadá, Paula Silva (directora).

Visual Anthropology Review, //etext.virginia.edu/VAR/ 